\section{TOOTH MAD MOBILES COMMENDED}

A photograph titled 'Mobiles gone tooth mad' by Professor Damien Walmsley of the University of Birmingham received a special commendation in a recent contest to find photographs on the theme of eHealth, mHealth (mobile health) and telehealth which could then be used in World Health Organisation publications covering such subjects. The contest was organised the World Health Organisation Global Observatory for eHealth in conjunction with the eHealth Strategy Office. Many entries were submitted by students and faculty from countries around the world and the winner featured community use of mobile phone technology.

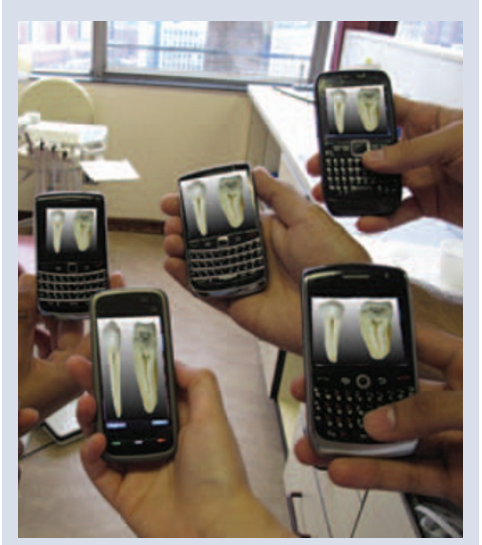

\section{MPS FOCUS ON CHILD DENTAL HEALTH}

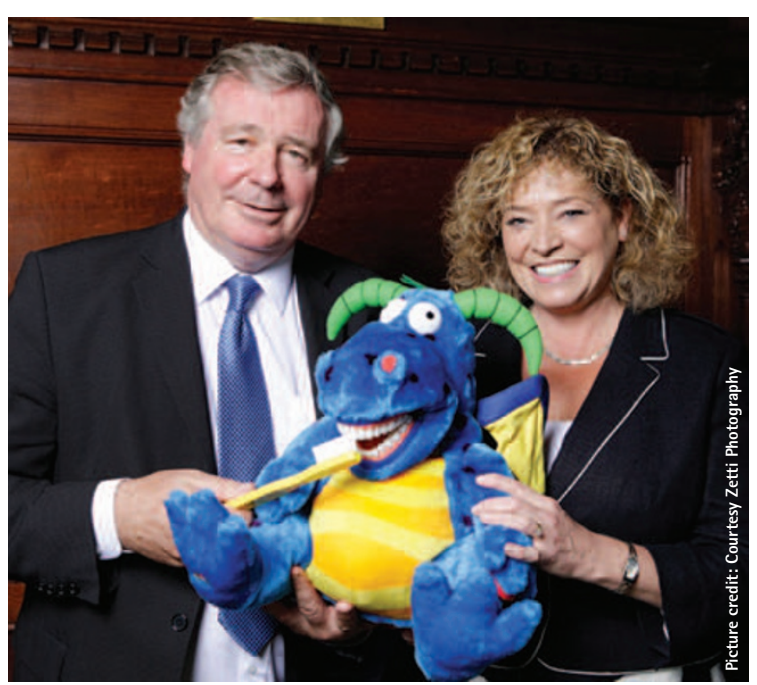

Sir Paul Beresford MP with Colette Bridgman, Consultant in Dental Public Health, NHS Manchester and a character used for oral health promotion

Members of Parliament have been urged to visit their local community dental services to see the challenges salaried dental teams face and the work they are doing to rise to them.

Speaking at the All-Party Parliamentary Group for Dentistry's 2011 annual reception, Chair of the group Sir Paul Beresford MP told fellow members of the House of Commons of a recent visit he'd made to a service in his constituency and recommended they do the same. Colette Bridgman, Consultant in Dental Public Health at NHS Manchester, told guests about the work being done to encourage non-attending children into regular dental care and the transforming effect the scheme has on their lives, producing not just improved oral health but also better school attendance and concentration in classes.

\title{
WHY DO CONTRACTS GO WRONG?
}

The University of Liverpool is leading a threeyear research study into NHS dental contracting. Researchers are exploring what 'successful' dental contracting looks like and why things go wrong. They are seeking to understand the role of trust, power imbalances, patient demand and political concerns.

'NHS contracts have been used increasingly since the 1990s as a form of resource allocation, although whether they actually save money by increasing efficiency is debatable,' said Dr Rebecca Harris, leader of the research team. 'When contracts are used to manage health care there is a danger that either party may exploit loopholes to maximise their self-interest. One way of addressing the problem is by strengthening relationships.'
The study, which began last October, focuses first on case studies of two or three dental practices and one medical practice within each of six PCTs in Northern England. Using a combination of interviews, documentary analysis and non-participant observation of contract negotiations, researchers will determine common themes which will then be tested by surveying a wider range of dentists beyond the six PCTs and commissioners from a further eight PCTs.

www.liv.ac.uk/cwgds
HONOURS AND AWARDS

Queen's Birthday Honours Bedford-based orthodontist Chris Kettler has been made a Member of the Order of the British Empire (MBE). James Rennie, former dean of postgraduate dental education at the Scottish Council for Postgraduate Medicine and Dental Education, has been made a Commander of the Order of the British Empire (CBE). Professor of dental research at Griffith University, Queensland, Australia, Newell Johnson, who is also emeritus professor of oral health, King's College, London, has been made a Commander of the Order of St Michael and St George (CMG).

\section{Honorary Doctorates}

Professor Bruce Matthews of the Department of Physiology, Bristol University, has received an honorary doctorate degree from the Mahidol University, Thailand. Professor Matthews has worked in the field of the physiology of dental pain for over 30 years and is internationally known and respected for his research. He has visited the Mahidol University to perform periods of dental research with a colleague over a number of years and is regarded as a distinguished visitor

Professor William Saunders, who played a major role in establishing Aberdeen's new Dental School, has received an honorary doctorate from the University of Aberdeen.

International Dentist of the Year Dr Ameed Abdul-Hamid was named International Dentist of the Year 2011 at the James Hull Associates annual conference dinner in June. Dr Abdul-Hamid has worked tirelessly to forge relationships with international universities and the Saudi Department of Health to launch the Arab Academy of Oral Health and the Saudi British Medical Forum to promote the ties between healthcare organisations in the UK and Saudi Arabia. The Academy will be based at Eastman ICED and the opening is planned for September. 